\title{
Gesprek oor ons moraliteitskrisis ${ }^{1}$
}

\author{
J.H. van Wyk \\ Dept. Dogmatologiese Vakke \\ HTS/PU vir CHO \\ POTCHEFSTROOM
}

\section{INLEIDING}

In 'n gesprek oor ons moraliteitskrisis moet tussen moraal en moraliteit - en ook tussen sede en sedelikheid - onderskei word. Moraal (sede) is wat die mens nou eenmaal dóen en moraliteit is wat die mens behóórt te doen of nié behoort te doen nie. Hierdie behorensmatige aspek raak egter nie net die mens se konkrete dade nie, maar ook dit wat daaraan voorafgaan, naamlik sy gesindheid, én dit wat daaruit voortvloei naamlik die gevolge van sy dade. Omdat die mens 'n relasionele wese is, kan hy immoreel optree in sy verhouding tot God en sy medemens maar ook teenoor die natuur.

Die woord krisis dui op: oordeel, beslissing, keuse, seleksie. Dit beteken dat 'n beslissende stadium of keerpunt bereik is, dat 'n oordeel gevel en 'n keuse gemaak moet word - 'n keuse tussen wat God voorskryf of wat die mens voorskryf.

\section{AGTERGROND}

Reformatories benader, moet ons opmerk dat die moraliteitskrisis met die sonderal begin het. Was daar geen sondeval nie, dan was daar geen krisis nie, ook geen moraliteitskrisis nie. Adam en Eva is die eerste moraliste op aarde. Tog is dit ook waar dat hierdie krisis in elke eeu nuwe dimensies vertoon en nuwe gestaltes aanneem.

Wanneer tans van moraliteitskrisis gepraat word, hou dit in 'n groot mate verband met die opkoms van die 'Nuwe Moraal', veral sedert die sestigerjare van ons eeu nie. Met 'Nuwe Moraal' word dan bedoel nie maar net 'n koerswysiging ten opsigte van die tradisionele moraal as sodanig nie, maar veral 'n verandering ten opsigte van die fundering van moraal. En dít hang weer in 'n groot mate saam met 'n relativering van die Skrif as gesagvolle Woord van God.

1 Hierdic artikel moet onderskei word van dic voordrag wat dic outeur in 1992 tydens die konferensic oor dic moraliteitskrisis in Pretoria gelewer het. 
In ons eeu het die 'Nuwe Moraal' veral twee besondere woordvoerders gevind in die persone van Joseph Fletcher en John A. T. Robinson. Ek gee ietwat meer aandag aan hierdie twee figure aangesien by hulle nagenoeg alle tendense van die Nuwe Moraal terug te vind is.

Joseph Fletcher se boek Situation Ethics van 1966 dra nie verniet die subtitel "The New Morality" nie. Hy kies baie duidelik vir ('n ekstreme vorm van) situasie-etiek wat antilegalisties is en waarin "only love and reason really count when the chips are down" (1966:31). "Whether any form of sex (hetero, homo, or auto) is good or evil depends on whether love is fully served" (1966:139). "The new morality, situation ethics, declares that anything and everything is right or wrong, according to the situation" (1966:124). Dít dien dan as reaksie op die vraag of voorhuwelikse seks, dobbel, steel, genadedood, aborsie, leuen, bedrog, kontrakbreuk ensovoorts reg is. Hy kies doelbewus vir 'n etiek wat deur pragmatisme, relativisme, positivisme en personalisme gekleur is (1966:40 e.v.).

John Robinson, wat oornag bekend geword het met sy boek Honest to God, sluit baie nou by Fletcher aan (vgl. 1964:112-128; 1967:53-56; 1971:16-61). Ook sy etiek is sterk anti-metafisies en anti-supranaturalisties (1964:120-121), asook anti-legalisties - reëls geld nie! (1964:117). Soos Fletcher kies ook Robinson vir 'n radikale situasie- en liefde-etiek (1964:122 e.v.). Hy argumenteer dat niks op sigself as verkeerd gekwalifiseer kan word nie; 'n mens kan byvoorbeeld nie van die standpunt uitgaan dat seksuele verhoudings voor die huwelik of egskeiding op sigself verkeerd is nie natuurlik kán dit verkeerd wees -, maar die enigste wat op sigself kwaad is, is gebrek aan liefde (1964:125; 1967:53,55). Die kenmerke van die Nuwe Moraal is duidelik:

- dit is anti-metafisies: die spreke oor 'n verhewe God het 'n probleem geword;

* dit is anti-absolutisties: daar kan nie sprake wees van absolute norme in die Bybel nie;

- dit is anti-legalisties: die wet maak dood, die liefde laat lewe; mense is belangriker as norme;

* dit is anti-kasuilsties: die situasie bepaal die morele keuse.

In 'n baie groot mate word die vraag na goed en kwaad uitgemaak deur die outonome mens wat met sy kritiese rede vanuit die situasie die morele keuse maak.

Natuurlik is alles in die Nuwe Moraal nie sleg nie. Die aandag vir humaniteit, situatiwiteit, relatiwiteit, ensovoorts is seker nie onbelangrik nie (vgl. Kuitert, 1970:183-196; Fackre in Bennett, 1967:67-87; Heering, 1969; De Graaf, 1969:38 e.v.). Maar die eensydighede, oorbeklemtonings, valse teenstellings en foutiewe 
vertrekpunte is nie teologies verantwoord nie (vgl. Lunn \& Lean, 1967; Hughes, 1983:67-79; Velema, 1974:46-57). Wat ons nodig het, is 'n humane en nie 'n humanistiese etiek, 'n relasionele en nie 'n relatiwistiese etiek, 'n situasie- en nie 'n situatistiese etiek nie; samevattend, 'n teologiese etiek wat erns maak met die Woord van God en die God van die Woord én 'n konkrete etiek wat indaal in ons gebroke werklikheid en gestalte help gee aan 'n goeie lewe voor die aangesig van God en mens.

Ek wil graag in hierdie verband na nog én sprekende voorbeeld verwys wat na die laaste vergaderings van die Gereformeerde Ekumeniese Sinode/Raad (GES/R) dikwels in die nuus was, en dit is die standpunt van die Gereformeerde Kerken in Nederland (GKN) oor Skrifgesag en homofilie, veral soos vervat in die dokumente God met ons (GKN, 1981), 'n dokument wat weliswaar onder revisie is (1985), en Homophilia (1981; vgl. GKN, 1972). Dit is duidelik dat daar tussen die twee rapporte 'n noue verband bestaan: die rapport oor homofilie moet gesien word as 'n konsekwensie van die studie, God met ons, skryf die GKN aan die Interim-komitee van die GES (6 Okt. 1987). Die dokument, God met ons, wat oor die aard van die Skrifgesag handel en ook aan etiese vrae aandag gee (1981:90-103), word in 'n groot mate beheers deur' $n$ filosofiese beskouing oor 'n relasionele waarheidsbegrip. Dit gaan nie om 'n objektiewe waarheid in die Skrif wat subjektief toegeëien moet word nie, maar oor 'n ineenstrengeling van albei (1981:13). In die opvolgstudie van 1985 is die relasionele waarheidsbegrip as vertrekpunt weggelaat, maar die konsep bly nog 'n rol speel. Samevattend: uit hierdie Skrifbeskouing volg dan dat dit nie verkeerd is om te konkludeer dat die homoseksuele aard en daad van mense moreel verantwoord kan wees nie.

Dit is duidelik dat daar tussen Skrifbeskouing en morele praktyk die allernouste verband bestaan, of as u wil, tussen dogmatiek en etiek, leer en lewe. 'n Foutiewe Skrifbeskouing loop uit op 'n foutiewe moraliteit.

Die probleem is egter groter, want ' $n$ juiste Skrifbeskouing bring nie noodwendig en outomaties 'n korrekte moraliteitsbeskouing met hom mee nie. In Suid-Afrika is ons maar te duidelik bewus daarvan dat, met 'n gereformeerde Skrifbeskouing en al, op foutiewe wyse 'n teologiese regverdiging van 'n bepaalde politieke beleid gegee is (vgl. onder andere J.D. du Toit 1955:5-21; E.P. Groenewald in Cronje, 1947:40-67). Ek voeg hier onmiddellik daaraan toe dat die manier waarop in sekere vorme van politieke teologie aan rewolusie 'n teologiese onderbou voorsien word, 'n ewe groot dwaling is.

By 'n juiste Skrifbeskouing kom dus 'n juiste Skrifgebruik en Skrifberoep ter sprake - 'n aspek wat ' $n$ breë onderwerp op homself is en waarop ek tans nie verder ingaan nie (vgl. verder Van Wyk, 1986:15-17, Velema, 1987:16-18). 
Oor die agtergronde wat morele krisisse veroorsaak is genoegsaam uitgewy. Voorts word enkele konkrete probleemvelde aangeraak wat wêreldwyd, maar ook in SuidAfrika, hoe langer hoe meer onrusbarende afmetings aanneem. Hierdie probleemvelde le veral op die terrein van die makro-etiek.

\section{KONKRETISERING}

\subsection{Moraliteit en polemologie}

Oorlog (en geweld) en 'n oorlogsmentaliteit oefen 'n geweldige invloed op 'n samelewing uit. Die effek en nagevolge van die twee wêreldoorloë op die wêreld - en veral die Europese samelewing - was verpletterend. Stel u immers 'n situasie voor waar, vir 'n periode van vyf jaar, die doodmaak van mense, owerspel, verkragting, lieg en bedrieg, diefstal en blinde gehoorsaamheid die gewone gang van sake is, en dit alles op 'n skaal wat miljoene mense raak, en die vraag lê voor die hand: hoe moet so 'n samelewing ooit weer na normaal terugkeer?

Ook in Suid-Afrika moet ons betrokkenheid by onrus- en oorlogsituasies sy tol eis. Binnelands kry ons al hoe meer met 'n rewolusionêre oorlog te doen terwyl die Angolese oorloë sy merk gelaat het. Die gebruikmaking van geweld word al hoe meer aanvaarbaar, geromantiseer selfs, sodat tereg opgemerk is dat ons mense vanweë die hoë blootstellingsfrekwensie aan geweld 'gedesensitiveerd' raak. Dit is ook swak opvoedkunde om kinders byvoorbeeld van kleins af met oorlogspeelgoed op te voed en sodoende hulle krygslus aan te wakker. En dan is nog nie eers verwys na moontlik die grootste gevaar van die mensdom vandag nie, naamlik 'n kernoorlog (vgl. Van Wyk, 1984:4-6). Nie net bedreig so 'n kernoorlog ons siéning van moraliteit nie - hoe lyk die moraliteit van mense wat op 'n vulkaan woon? - maar dit bedreig moraliteit as sodanig: sal daar ná so 'n vernietigende kernoorlog nog ménse oor wees om moreel te probeer lewe? Einstein het iewers die opmerking gemaak dat as die derde wêreldoorlog met atoombomme gevoer sou word, sal die vierde met knopkieries gevoer moet word (vgl. Van Wyk, 1984:3). Ek hoop van harte dat ons Suid-Afrikaanse regering nie probeer saamspeel in hierdie magspel nie sodat Afrika 'n kernwapenvrye gebied kan bly.

\subsection{Moraliteit en politikologie}

Nou aansluitend by bogenoemde is die morele vrae wat verband hou met sake soos menseregte, rassisme, trekarbeid, ensovoorts - vrae dus wat saamhang met menswaar- 
digheid. Die morele vraag dring homself na vore of ons samelewing so ingerig is dat elke mens volledig tot sy reg kan kom, en as vrye mens voor die aangesig van God sy roeping kan volvoer. Of is ons samelewing sodanig gestruktureer dat dit sommige bevoordeel en ander benadeel? Het ons met gelegaliseerde onreg te doen? Is ons beoefening van politiek nie te sterk ideologies gekleur nie?

Die Christelike karakter van ons politieke moraliteit moet uit die politieke realiteite afgelees kan word, want 'n boom word aan sy vrugte geken. As die vrugte van ons politieke realiteit wrang is, dan moet die morele fundering daarvan vals wees. Hoeveel Christelikheid sit daar in ons politiek, of beskou ons dit as 'n terrein waarop godsdiens niks te sê het nie? Moet ons God dan nie $66 \mathrm{k}$ in die politiek dien nie? Vanuit die Christelike etiek beskou, het ons geen ander opsie nie as om die groot morele eise van die koninkryk van God ook in ons aardse politiek te laat gestalte kry (vgl. Van Wyk, 1986:186-197; verder Engelbrecht, 1982:75 e.v., De Klerk, 1980:32-42; Esterhuyse, 1979; 1982:94 e.v.; Degenaar, 1976:18-29; 1980). Daar bestaan tans konsensus dat 'n handves oor menseregte, wat Skriftuurlik gemotiveer is en nie humanisties gefundeer is nie, die politieke moraliteit van ons Suid-Afrikaanse samelewing kan verhoog (vgl. Van Wyk, 1987:31-39; Du Toit, 1984, 1988).

\subsection{Moraliteit en demografie}

Demograwe skilder 'n donker prentjie van die wêreld- en Suid-Afrikaanse bevolking. 8000 jaar gelede was daar glo sowat 5 miljoen mense op aarde, met Christus se geboorte 300 miljoen en tans oor die 4000 miljoen. Verdubbeling van die bevolking het 8000 jaar gelede 1500 jaar geneem en tans neem dit 35 jaar. Die totale bevolking van Suid-Afrika was rondom 1970 sowat 20 miljoen en volgens berekening sal dit teen die jaar 2000 sowat 60-70 miljoen wees en teen die jaar 2070 sowat 700 miljoen (vgl. Van Wyk, 1986:162-170). Demograwe sê dat Suid-Afrika vanweë sy beperkte natuurlike hulpbronne, nie meer as 70 miljoen mense kan onderhou nie.

Met hierdie gegewens staan ons natuurlik midde in 'n moraliteitskrisis ten opsigte van huweliksetiek en voorhuwelike etiek (vgl. Esterhuyse, 1980; Heyns, 1981). Is groot gesinne nog verantwoord (vgl. De Bruyn, 1985)? Moet ons groot gesinne vir blankes bepleit en klein gesinne vir swartes? Is dit nie 'n gevaarlike dubbele moraal nie? Wat is die doel van seksualiteit: slegs vir kinderverwekking, soos soms gemeen is, of ook ter wille van genot? (vgl. Kroeze, 1970). Voeg hierby sake soos die vrye beskikbaarheid van voorbehoedmiddels, die openlike propagering van vrye seks, die toename in homoseksualiteit en kindermolestering en die nuwe dimensie wat met vigs ingetree het, en dis duidelik dat ons hier oor 'n mynveld van morele vraagstukke beweeg. 
Ek meen dat die gereformeerd-Christelike etiek hier koers gehou het, selfs al moes 'n paar regstellings aangebring word. Seksualiteit is baie duidelik ten nouste met die huwelik verbind, maar dan met sy dubbele doelstelling van kinderverwekking en uitdrukking van liefde tussen man en vrou (prokreasie én rekreasie). Wat die kindertal betref, word gestreef nie na die minimum aantal kinders nie, ook nie na die maksimum nie, maar na die optimum, dit wil sê daardie getal wat in elke konkrete (gesin-)situasie (goeie situasie-etiek!) voor die Here verantwoord is. En dit geld dan vir alle bevolkingsgroepe ter wêreld. Die mens is geroep om die aarde te vul en nie om daarop te vervuil nie. Dit beteken dat daar 'n dag kan kom - en vir sommige nasies het dit seker al aangebreek. dink aan Indië en China - dat ontdek sal word dat dít waartoe die Here opdrag gegee het, naamlik om die aarde te vul, bereik is. Dán staan die mensheid weer voor ' $n$ volkome nuwe fase ten opsigte van die huweliksetiek.

\subsection{Moraliteit en ekologie}

Ons het begin deur te sê dat moraliteit ook die mens se verhouding tot die natuur raak. Die mens kan ook immoreel met sy omgewing omgaan (vgl. Van Wyk, 1986:152-161). Hy kan die water op so 'n manier besoedel dat dit nie alleen vir die dierelewe nie maar ook vir die mens self 'n al hoe groter gevaar inhou. Dink maar aan die wyse waarop byvoorbeeld die Vaalrivier aan afvalstowwe blootgestel word. Daar is kenners wat meen dat die oseane in ashope verander, veral as in gedagte gehou word dat jaarliks twee tot tien miljoen ton olie en olieprodukte in die oseane gestort word.

Lugbesoedeling is ook voortdurend aan die toeneem sodat daar al gevrees word vir'n wanbalans tussen die hoeveelheid suurstof en koolsuurgas op aarde.

Heeltemal sorgwekkend is die besoedeling van die omgewing deur middel van veral rommelstrooi. Elke mens is verantwoordelik vir ongeveer drie kilogram afval per dag en - hoe meer mense, hoe meer afval. En hoe meer gesofistikeerde uitvindings (plastieksakke byvoorbeeld), hoe groter word die probleem.

Die omgewingsbesoedeling het reeds sulke afmetings aangeneem dat 'n toesprakie hier of daar heeltemal ontoereikend is; iets sal gou en groot gedoen moet word. Die vraagstuk mag nie in die prediking ontbreek nie en in die kategese en pastoraat moet dit indringende aandag ontvang. Mense moet geleer word om die aarde op te pas as skepping van God en woonplek van die mens, en om dit nie te verniel nie (Gen. 2:15).

Ten slotte word ons aandag op enkele rigtingwysers gevestig. 


\section{RIGTTNG}

\subsection{Kennis van die Woord}

Tweërlei kennis is by morele kwessies van deurslaggewende betekenis naamlik kennis van die Woord en kennis van die werklikheid.

Met kennis van die Woord word natuurlik nie 'n koue verstandskennis van 'n aantal Goddelike wette bedoel nie, nee; eintlik gaan dit bo alles nie om die Woord van God nie maar om die God van die Woord; of nog beter: dit gaan in die Woord om God, om die kennis van die wil van God (Kol. 1:9), dié God wat ons tegemoettree as Vader en Seun en Gees, as Skepper, Redder en Vernuwer.

Dis alleen in die lig van die Bybel as Woord van God dat die mens tussen goed en kwaad kan onderskei (vgl. Rom. 16:19, Heb. 5:14) en die oersonde kan vermy deur sélf te probeer uitmaak wat goed en kwaad is (Gen. 3). Die kriterium vir goed en kwaad moet uit genade aan die mens gegee word; hy kan dit nie in vrye outonomie self uitdink nie.

Daarmee is nie gesê dat antwoorde op alle morele vrae pasklaar in die Skrif te vind is nie. Die breë lyne (beginsels sou sommige wou sê) is wel daar, maar die toepassing daarvan moet nog gemaak word (sommige mense praat hier van nome). Ons moet onderskei wanneer iets Skriftuurlik verantwoord is, dit wil sê wanneer iets direk uit die Skrif afgelei kan word, en wanneer iets Skrifmatig is, dit wil sê alleen by wyse van indirekte afleiding begrond kan word. Soos reeds gestel: 'n goeie Skrifbeskouing waarborg nie outomaties 'n goeie Skrifberoep nie - daarvoor is mér nodig, onder meer gebed, die leiding van Gees en die meeluister met ander gelowiges (Ef. 3:18) (vgl. Van Wyk, 1984:204).

\subsection{Kennis van die werklikheid}

Engelbrecht (s.j.:23) maak die volgende raak opmerking:

Ek begin al hoc meer oortuig raak dat daar in dic Christelike Etiek die meeste gesondig word, nic aan die kant van dic Skrif en Skrifgebruik nic, maar aan dic kant van dic noukeurige en objektiewe vasstelling van dic sake wat beoordecl moet word.

Hierdie stelling kan met reg beaam word: die Woord moet by die werklikheid gebring word. In dié sin is slegs kennis van die Woord onvoldoende as die werklikheid (die situasie) waarop dit betrekking het onvoldoende of eensydig in berekening gebring word. Wie oor oorlogsetiek of omgewingsetiek of politieke etiek handel, maar niks 
weet van die konkrete problematiek nie, kan onmoontlik met 'n korrekte Skrifberoep vorendag kom. Hierdie waarheidsmoment het die situasie-etiek tereg benadruk (vgl. De Graaf, 1969:42-45). Die waarheid kom wel nie uit die situasie op nie maar die waarheid moet in 'n bepaalde situasie gestalte aanneem.

Daarom: ons gebruik die Skrif dikwels so verkeerd, eenvoudig omdat ons die werklikheid om ons so swak ken. Toegepas: As ons die swart wêreld om ons beter geken het, al die hartseer en pyn, die irritasies en frustrasies, sou ons nie veel makliker 'n Skriftuurlike oplossing in ons politieke moraal gevind het nie? Ons het alte maklik met die Skrif omgegaan, los van die konkrete werklikheid om. En sodoende is die moraliteitskrisis verhoog.

In die Bybel is daar antwoorde op al ons morele vrae - miskien nie altyd direk nie, maar tog. Soms moet daar geworstel word om die wil van God te ontdek, soms selfs bloed gesweet word, soos Christus, maar ons het die belofte dat die Gees die gelowiges in die waarheid sal lei (Joh. 16:13), selfs al dwaal hulle soms ver af. Heeltemal verdwaal kan hulle egter nooit.

\section{BIBLJOGRAFIE}

BENNETT, J.C. et al. 1967. Storm over Ethics. United Church Press/The Bethany Press.

CRONJE, G. 1947. Regverdige rasse-apartheid. Stellcnbosch : CSV-Bockhandel.

DE BRUYN, P.J. 1985. Verantwoordc ouerskap. Potchcfstroom : CJBF.

DEGENAAR, JJ. 1976. Moraliteit en politick. Kaapstad : Tafelberg.

DEGENAAR, JJ. 1980. Voortbestaan in geregtigheid: Opstelle oor die politicke rol van dic Afrikaner. Kaapstad : Tafelberg.

DE GRAAF, J. 1969. De cthiek van het immoralismc. Nijkerk : Callenbach.

DE KLERK, Willem. 1980. Politieke gesprek. Johanneshurg : Perskor.

DU TOIT, J.D. \& DU TOIT, S. 1955. Dic Afrikanse rasscbeleid en die Skrif. Potchefstroom : Pro Rege Pers.

DU TOIT, DA. (red.) 1984. Menseregle. Kaapstad : Tafelberg.

DU TOIT, D.A. 1988. Dic mens en sy regtc: Geloof en praktyk in Suid-Afrika. Kaapstad : Zebra.

ENGELBRECHT, B. 1982. Ter wille van hicrdie wereld: Politieke en Christelike heilsbelewing in SuidAfrika. Kaapstad : Tafelberg.

ENGELBRECHT, B.J. s.j. Opmerkings rondom die basiese probleme van die teologiese etiek. Hervormde Teologiese Siudies, 34(3):13-23.

ESTERHUYSE, W.P. 1980. Die mens en sy seksuele moraal. Durban : Buttcrworth.

ESTERHUYSE, W.P. 1982. Die pad van hervorming: Beskouinge oor die noodsaaklikheid van strukturele hervorming in Suid-Afrika. Kaapstad : Tafelberg.

FLETCHER, Joseph. 1966. Situation Ethics: The New Morality. London : SCM Press.

GEREFORMEERDE KERKEN IN NEDERLAND. 1972. Over mensen die homofiel zijn. Utrecht : Kerkinformatic.

GEREFORMEERDE KERKEN IN NEDERLAND. 1981. God met ons: Over de aard van het Schriftgezag. Leusden : Kerkinformatic. 


\section{GKN}

kyk (iEREFORMEERDE KERKEN IN NEDERLAND.

GROENEWALD, E.P. 1947. Apartheid en voogdyskap in dic lig van dic Hcilige Skrif. (In Cronjc, G.

Regverdige rasse-apartheid. Stellentosch : CSV-Bockhandel. p. 40-67.)

HEERING, H.J. 1969. Ethick der voorlopigheid. Nijkerk : Callenbach NV.

HEYNS, J.A. 1981. Elick van dic liefde. Pretoria : Daan Retief.

HUGHES, P.E. 1983. Christian Ethics in Secular Society. Grand Rapids : Baker Book House.

KROEZE, J.H. 1970. Bybel en seks. Braamfontein : De Jong.

KUITERT, H.M. 1970. Anders gezegd : Een verzameling theologische opstellen voor de welwillende lezer. Kampen : Kok.

LUNN, A.\& LEAN, G. 1967. The New Morality. London : Blandford Press.

REFORMED CHURCHES IN THE NETHERLANDS (General Synod). 1981. Homophilia: A Report on Biblical Dala.

REFORMED CHURCHES IN THE NETHERLANDS. 1985. Sequel to God with Us. (Appendix to Communication 11 to the Agenda RES 1988).

ROBINSON, John A.T. 1964. Eerlijk voor God. Amsterdam : Ten Have.

ROBINSON, John A.T. 1967. Maar dal kan ik nict getoven! Amsterdam : Ten Have.

ROBINSON, John A.T. 1971. Christelijke vrijheid in cen tolerante maatschappij. Baarn : Ten Have.

VAN WYK, J.H. 1984. Etick van vrede: 'n Teologies-eliese evaluering van die Christenpasifisme. Stellenbosch : Cabo.

VAN WYK, J.H. 1986. Gesindheid en gestalte. Pretoria : NG; Kerkbockhandel.

VAN WYK, J.H. 1987. Elick en menseregte. In die Skriflg, 21(81):31-39, Maart.

VELEMA, W.H. 1974. Christen zijn in deze wereld. Kampen : Kok.

VELEMA, W.H. 1987. Wet en Evangelie. Kampen : Kok. 
